\title{
Understanding 'Experiences' from the perspective of children and adolescents
}

\author{
Snigdhasree Bhattacharya ${ }^{1}$ \\ Uma Hirisave ${ }^{2}$ \\ N. Janardhana ${ }^{3}$ \\ ${ }^{1}$ Ph.D. Scholar, Department of Clinical Psychology, \\ ${ }^{2}$ Professor, Department of Clinical Psychology, \\ ${ }^{3}$ Assistant Professor, Department of Psychiatric Social Work, \\ National Institute of Mental Health and Neurosciences, Bangalore. \\ E-mail - snighdhab1@yahoo.com
}

\section{ABSTRACT}

The study aimed at to explore how children and adolescents conceptualize experiences in their day to day life. Apart from this the study also aimed to explore various experiences in children and adolescents. Focus Group Discussions were conducted with school going children of different age ranges. The discussions were audio taped, transcribed and content analyzed. The understanding of 'various experiences' from the perspectives of children and adolescents are illustrated and the qualitative analysis findings are discussed in this paper. Comparisons of various responses across developmental stages and between the two genders are also discussed. Having discussed the 'various experiences' of children and adolescents, the paper elaborates on application of the findings in development of a tool for future research.

Key words: experiences of children and adolescents, defining experiences, positive experiences, negative experiences

\section{INTRODUCTION}

The word 'experience' is perhaps the most commonly used word in behavioural research with children and adolescents. Most researchers use the questions like 'Could you share your experience in school? etc, while researching children and adolescents' experiences. However the word 'experience' as well as 'various types of experiences' of children and adolescents are largely conceptualised by adults. As per Webster's dictionary, 2010, Experience is defined as a direct observation of or participation in events as a basis of knowledge. It can be something personally encountered, undergone, or lived through. Experience, most often in psychology is defined either on the basis of philosophy or the dictionary version. [1-2]

Studying experiences is of immense value as, the ability to organize and understand our experiences are a basic part of how we make sense of our world. From a very early age, children are actively constructing how things happen, and forming memories of the event of their lives [3]. 
Experiences of a child or an adolescent can be both positive and negative. Positive experiences are usually gratifying and fulfilling, where as negative experiences are damaging and often traumatic. Negative experiences are damaging and often traumatic. There are a wide variety of negative experiences which includes accidents, painful medical procedures, or life changing emotional events and abuse such as physical or sexual abuse or serious neglect [4]. Children's early experiences and relationships build a foundation for their subsequent learning and social interactions. A child is most likely to reach her full potential if he/she experiences consistent, predictable, enriched, and stimulating interactions and positive experiences in a context of attentive and nurturing relationships. However research on positive experiences is very limited.

Traumatic experiences can have a devastating impact on the child, altering their physical, emotional, cognitive and social development. Traumatic events in childhood increase risk for a host of social (e.g., teenage pregnancy, adolescent drug abuse, school failure, victimization, anti-social behaviour), neuropsychiatric (e.g., posttraumatic stress disorder, dissociative disorders, conduct disorders) and other medical problems (e.g., heart disease, asthma) [5]. Coming to the processing of these experiences, in a study comparing the quality of children's memory for a stressful life event with positive event, investigators found that the children reported different kinds of information about the two types of events. Memories of stressful events included more information about thoughts and emotions, whereas positive events had more descriptive details [3].

However memory would be only one component of processing an experience, cognitive appraisal, emotional processing etc would also be playing a role.

Therefore there is a need for more detailed understanding about the construct of 'experience', 'various experiences both positive and negative' and 'processing of an experience' from the perspective of children and adolescents. Given this lacuna, the current doctoral work has been designed to understand how children and adolescents conceptualize and understand various experiences. The study also aims to develop a scale to assess experiences of children and adolescents and establish the psychometric properties of the scale. The unique feature of this study is that the tool will be developed purely based on the experiences reported by children and adolescents. This study is a part of a larger study being carried out in the Department of Clinical Psychology, National Institute of Mental Health and Neuro Sciences (NIMHANS), Bangalore, by the first author under the guidance of the second and third authors. The procedure and method of the study has been approved by the scientific and ethical review committee in NIMHANS. The present paper elaborates on the pilot study findings.

\section{METHODOLOGY}

The study aims to develop a scale to assess experiences in children and adolescents. The objectives of the study include exploring how children and adolescents conceptualize experiences in their day to day life and gaining understanding about their various experiences.

The study was cross sectional in nature. Qualitative method was used to investigate how experiences were conceptualised and events leading to these experiences. The universe of the study was children and adolescents studying in school (from $3^{\text {rd }}$ standard to $10^{\text {th }}$ standard) in Bangalore city (They will be referred to as participants in the present paper). A total of 67 children and adolescents' belonging to families of middle socio economic status were recruited for the study. 
A focus group discussion guide was prepared after reviewing various studies that have used focus group discussions with children and discussion with the research guide [6].

Development of the Focus Group Discussion Guidelines -

- It was decided to have minimal leads and probes for the FGDs, as the study attempts to understand the child's perspective.

- Steering the discussion using specific probes would perhaps be leading the discussion to a pre determined objective or goal.

- Therefore the discussion focused on three major questions- defining experience, various positive experiences and various negative experiences.

- The opening question, leads and probes are simplistic lay descriptions of positive and negative experiences. This was done so that the discussion is less intimidating ensuring free flow of thought.

\section{Procedure of the Study}

Two schools consented to participate in the study. Three classes were finalized for the pilot study $\left(4^{\text {th }}, 7^{\text {th }}\right.$ and $10^{\text {th }}$ Standard $)$. The three classes were representative of the three age ranges (8-10yrs, 11-13yrs and 14-16yrs). Fifteen students were randomly selected from these classes (Example - Roll Numbers 30 to 45, or the middle rows of the class, or last three benches). Written Informed consent was taken from the head of the institute and parents. Assent was taken from the child for participation in the study.

Focus group discussions were conducted in three sessions.

- First Session -The students were given the consent forms and explained the rationale of the study and orientation to the concept of focus group discussions.

- Second Session - The students, who got the filled up consent form, were called for the second session. They were either asked to read the assent form or the assent form was read out to them, depending on the age levels. Some basic rules of confidentiality was explained in this session. An icebreaker game was introduced to increase levels of comfort.

- Third Session - the main focus group discussion was conducted.

A total of 6 focus group discussions were conducted for the pilot study. 3 girl groups and 3 boy groups of the three age levels. The focus group discussions were audio taped, transcribed, coded and content analyzed.

\section{RESULTS}

The table below (Table 1) shows the number of participants as well as the gender of the groups. The number of participants in the younger groups is slightly higher than the older groups. The number of participants varies in each group due to factors like - absenteeism on day of the FGD, not bringing the consent form on the day of the FGD and sometimes also not consenting to participate in the study. 
Table 1 - Description of the sample who participated in the Focus Group Discussions

\begin{tabular}{cccc|}
$\begin{array}{c}\text { Group } \\
\text { No }\end{array}$ & $\begin{array}{c}\text { Number of participants } \\
\mathbf{N}=\mathbf{6 7}\end{array}$ & Class & Age Range \\
\hline $\mathbf{1}$ & 15 Boys & $4^{\text {th }}$ Std & $9-10 y e a r s$ \\
\hline $\mathbf{2}$ & 12 Girls & $4^{\text {th }}$ Std & $9-10 y e a r s$ \\
\hline $\mathbf{3}$ & 8 Boys & $7^{\text {th }}$ Std & $12-13 y e a r s$ \\
\hline $\mathbf{4}$ & 10 Girls & $7^{\text {th }}$ Std & $12-13 y e a r s$ \\
\hline $\mathbf{5}$ & 14 Boys & $10^{\text {th }}$ Std & $15-16 y e a r s$ \\
\hline $\mathbf{6}$ & 8 Girls & $10^{\text {th }}$ Std & $15-16 y e a r s$ \\
\hline
\end{tabular}

Table 2 -Defining and Understanding experiences according to the participants

\begin{tabular}{|c|c|c|}
\hline Age Range 8 to $10 y e a r s$ & Age Range 11 to 13 years & Age Range 14 to $16 y$ ears \\
\hline Experience teaches us. & $\begin{array}{l}\text { To handle things well in our } \\
\text { life we need experiences. }\end{array}$ & $\begin{array}{l}\text { Experience makes us } \\
\text { stronger. }\end{array}$ \\
\hline $\begin{array}{l}\text { Experience is what we } \\
\text { feel. }\end{array}$ & $\begin{array}{l}\text { Something that has } \\
\text { happened before to us is an } \\
\text { experience. }\end{array}$ & $\begin{array}{l}\text { Experiences are what our } \\
\text { feelings and memories are } \\
\text { made up of. }\end{array}$ \\
\hline $\begin{array}{l}\text { It is things we go } \\
\text { through. }\end{array}$ & $\begin{array}{l}\text { The incidents that keep } \\
\text { coming to our mind is } \\
\text { experience. }\end{array}$ & $\begin{array}{l}\text { Experience is each and } \\
\text { everything happening to us, } \\
\text { like right now is an } \\
\text { experience. }\end{array}$ \\
\hline $\begin{array}{l}\text { It is what should happen } \\
\text { and what should not } \\
\text { happen to us. }\end{array}$ & $\begin{array}{l}\text { Feeling happy or sad is an } \\
\text { experience. }\end{array}$ & $\begin{array}{l}\text { Experience is what we go } \\
\text { through and learn from. }\end{array}$ \\
\hline
\end{tabular}

Table 2 illustrates how the definitions and understanding of experiences are different at different age ranges. Table 3 highlights the various positive and negative experiences under the domains of peer relations, family relations and school related experiences. 
Table 3 - Various Themes of Positive and Negative Experiences under the different domains

\begin{tabular}{|c|c|c|}
\hline Domain & Positive Experiences & Negative Experiences \\
\hline $\begin{array}{l}\text { Peer } \\
\text { Relations }\end{array}$ & $\begin{array}{l}\text { Sense of belongingness and } \\
\text { acceptance from peers } \\
\text { Heterosexual Attraction }\end{array}$ & $\begin{array}{l}\text { Bulling by peers - name calling } \\
\text { Ostracisation } \\
\text { Being Blamed or Scapegoating }\end{array}$ \\
\hline $\begin{array}{l}\text { Family } \\
\text { Relations }\end{array}$ & $\begin{array}{l}\text { Sense of feeling loved and } \\
\text { accepted in a family }\end{array}$ & $\begin{array}{l}\text { Verbal Abuse by authority } \\
\text { figures } \\
\text { Favoritism/ Partiality/ } \\
\text { Differential Treatment } \\
\text { Witnessing Domestic } \\
\text { Violence/Unharmonious home } \\
\text { environment } \\
\text { Physical Abuse } \\
\text { Loss- Death, Threat of Death } \\
\text { Promises/ Commitments being } \\
\text { broken } \\
\text { Restrictions with the opposite } \\
\text { sex }\end{array}$ \\
\hline $\begin{array}{l}\text { School } \\
\text { Related } \\
\text { Experiences }\end{array}$ & $\begin{array}{l}\text { Achievement and } \\
\text { Recognition } \\
\text { Exploring Hobbies- beyond } \\
\text { academics }\end{array}$ & $\begin{array}{l}\text { Verbal Abuse by authority } \\
\text { figures } \\
\text { Favoritism/ Partiality/ } \\
\text { Differential Treatment } \\
\text { Physical Abuse }\end{array}$ \\
\hline $\begin{array}{l}\text { Experiences } \\
\text { when alone }\end{array}$ & & Sexual Abuse \\
\hline
\end{tabular}

\section{DISCUSSION}

The aim of the study was to explore how children and adolescents conceptualize experiences and enumerate various experiences in their day to day life. The participants of the study discussed their viewpoints and shared their experiences in the focus group discussions. The participants were free to share their own experiences as well as experiences in general in the group. The findings are a combination of their own experiences as well as general experiences. When the participants were asked to define the term 'experience' various insightful explanations were given across the age ranges. The responses can be classified further into major themes. Some themes under which the responses can be classified are -

- Lessons Learnt and Gaining Expertise through Experiences - Experience teaches us; Experience makes us stronger; Experience is what we go through and learn from.

- Emotional Component of Experiences - Experience is what we feel; Feeling happy or sad is an experience.

- Cognitive Component of Experiences - Experiences are what our feelings and memories are made up of; The incidents that keep coming to our mind is experience. 
- Experiences as personal events - It is things we go through; Something that has happened before to us is an experience.

- Experience is also seen as a Continuous Uncontrollable Process - It is what should happen and what should not happen to us; Experience is each and everything happening to us, like right now is an experience.

Therefore various responses of the participants have been classified into major themes. With a larger sample, more responses and some more themes, clear understanding on how children and adolescents conceptualise and understand experiences can be achieved. It would be interesting to congregate these themes to form one operational definition that would be applicable across all age ranges.

Positive Experiences that emerged in the focus group discussions were classified under the domains of peer relations, family relations and school related issues. The maximum positive experiences were mainly related peer relations and school related issues. Under peer relations, sense of belongingness has been seen as something that evolves in every stage. In the age group of 8-10 years having a best friend is considered as a positive experience (Eg - 'It's a nice experience when someone calls me their best friend...it makes me happy'). The participants in the age range 11-13 years reported having a friend to do things with, like being called for a pizza party or to play badminton with is considered as a positive experience. In the age range of 14-16 years the participants report that having a friend who trusts you, stands up for you and whom you can share your inner feelings with is a positive experience (Eg - 'having a friend who trust you no matter what...this feels good').

Apart from this heterosexual attraction was another positive experience reported. However it must be noted that this was found mainly in the age range of 14-16 years. Gender differences were also noted, while the female group viewed it as a form of a new evolving friendship, the male group viewed it as exploration of sexuality (Eg. 'The boys I grew up with, I feel we get along more now and like spending more time'). Similarly, an example of a response of a participant from the male group: 'Having girl friends, crushes and exploring pornography can be fun'. School related positive experiences were mainly in form of achievements in academics and participation in extracurricular activities. Making a niche in an area and earning accolades, appreciation and recognition for the same was reported as a positive experience. (Eg -'Getting to win a prize in sports day is a good experience'; 'The teacher making you the board leader and appreciate the thought for the day is a positive experience'; 'After failing, when you do well and the teacher tells it in front of the full class, we feel like on the top of the world'; 'whenever there is a program in school, the teacher asks me to sing for the inauguration, I feel very happy about it.'...).

In the domain of Family relations, themes in the younger age ranges 8-13 years were mainly - Surprise birthday party, receiving gifts when doing well in studies, Vacations and spending quality time with family. (Eg-'Sometimes parents may say that we will not celebrate your birthday this time, however once my parents woke me up at 12 in the night and wished happy birthday with a cake...it was my happiest $\left.d a y^{\prime}\right)$. However in the age ranges of $14-16$ years the themes were mainly around trust and having faith in their son/daughter irrespective of rumours and complains (Eg- 'when a neighbour told my mother that I was coming from school with a boy, my mother told that I know about my daughters whereabouts, don't worry...I felt very good'; 'Once a teacher complained in parent teacher meeting about me copying, but my father told me that he trusts me no matter what'). 
Negative Experiences that emerged in the focus group discussions were also classified under the domains of peer relations, family relations and school related issues. An additional domain of experiences when alone related to sexual abuse was also made. Maximum negative experiences reported by the groups were mainly in the domain of family relations. Verbal Abuse by authority figures in form of labelling by parents and teachers related to performance in studies as dull or lazy. The theme of Favoritism/ Partiality/ Differential Treatment was also reported in form of comparison with siblings and cousins (Eg -'My parents always buy things for my sister, who is in PG1, they tell next time for me because I am the older one...but next time never comes' ). The theme of Witnessing Domestic Violence/Unharmonious home environment was also reported in form of Fights between parents, financial pressures and fear of parents separating. (Eg - When my parents start arguing loudly I get so scared that they may start hitting each other...i try to stop them from arguing that time').

Physical Abuse in home context was reported in form of being locked in a room or slapped. However this was reported in age ranges $11-16$ years. ( Eg -'My father slapped me the moment I came home, because I had come late from tuitions...he didn't even allow me to explain, that I had met a friend on the way' ; 'My parents locked in the attic room, because I failed in maths for the whole day'). Experiences of loss in form of Death were reported by the participants. (Eg -'My grandfather's death hurt me a lot, I had spoken to him in the morning... when I got back from school, he had died...I still remember and feel bad about it.') Promises and Commitments being broken was reported by the younger age group of 8-10 years predominantly in form of parents not keeping up plans made about family outings, vacations and gifts that was previously promised. (Eg - When our parents say, we will buy you a dress if you get good marks...then later they say, I can't buy because I don't have the money').

The theme of restrictions with the opposite sex in family context was reported mainly by the participants between 14-16 years in form of setting stringent rules regarding interactions with the opposite sex - including cousins and childhood friends. (Eg- ' If my classmate calls who is a girl, my mother immediately starts lecturing me about, how friendship at this age is very problematic.... she has been a friend even earlier, how come it was not problematic then'). There is a significant overlap in the themes and content of negative experiences in the domain of school related experiences with family relations. In the domain of peer relations the major themes were bulling by peers and name calling; Ostracisation and Being Blamed or Scapegoating.

Bullying and name calling was found in age ranges $11-16$ years. The male groups reported abundant use of colloquial slang and slander. The female groups reported usage of certain names and abuses. (Eg - - labeling 'two headed snake' for some one who gossips etc). Ostracisation across age ranges was reported in form of not having friends to do things with, not being included in groups and being gossiped about and isolated. (Eg - 'Sometimes no one wants to be your friend if you don't do well in your exams....to make matters even worse, they spread rumors with which others also stop being friends'). However it must be noted that 'ostracisation' as a negative experience was reported a lot more in the female groups.

Scapegoating was reported in the younger age ranges of $8-10$ years mainly in context of siblings...especially younger siblings. (Eg - 'Sometimes the mistakes that our sister or brother does comes on us...and our parents say you are big, so it's your fault...but it was not my fault......for breaking a glass product at home'). Being blamed was reported by both male and female participants in age ranges 11-16 years. The female participants reported being blamed if and when they receive male attention. ( $\mathrm{Eg}$ - 'My father scolded me once saying, for the boy to follow, you must have smiled at him 
and given him some ideas too'). Interestingly the male participants of the discussion also reportedly feel that with the rise of sexual abuse, the gender is being blamed and held responsible.( Eg- 'With the rise in sexual abuse...the male gender is always blamed...it's both shameful and at times stressful as I don't feel that comfortable to hug my cousin sisters any longer... while sexual abuse is a bad experience, to be constantly doubted on because I am male is a bad experience too').

Under the domain of experiences when alone sexual abuse was an important theme that was found in the female groups from age ranges 11-16 years in form of being stared at by older men, followed, being touched inappropriately in crowded market places. (Eg - Some men may be even as old as my father, the way they look and stare is very uncomfortable'; If we go to any crowded place, especially in a theater which is dark, sometimes some boys try touching in a bad way, that's a bad experience'). Therefore to conclude with, the focus group discussions as part of the pilot study was able to -

- Understand how children conceptualize experiences.

- Various events leading to experiences in children and adolescents.

- How experiences constantly evolve in different developmental stages.

The findings of the study bring to light the scope for development of an operational definition of experiences from the perspective of children and adolescents. The research will try to understand more about how children understand and interpret, negotiate and feel about their daily lives. The main study will include a larger sample with participants belonging to higher, middle as well as lower socio economic status. The various experiences shared by the participants will lend itself to generating items, on the basis of which a scale will be constructed. Therefore the scale will be applicable to children and adolescents belonging to different back grounds. A pictorial version of the scale will also be developed, which will be applicable to younger children as well as those who may find it difficult to respond to statement format. These scales will prove to be a unique and important measure in the area of Child and Adolescent Mental Health.

\section{REFERENCES}

1. Greene S, Hogan D. Researching Children's Experiences: Methods and Approaches. (2nd Ed.): Sage Publishers; 2005.

2. Freeman M, Mathison S. Researching Children's Experiences. (1st Ed.): The Guildford Press; 2009.

3. Fivush R. Children's recollections of traumatic and non traumatic events. Dev Psychopathol 1988;10(4):699-716.

4. Ziegler D. Traumatic Experience and the Brain: A Handbook for Understanding and Treating Those Traumatized As Children. (2nd Ed.): Acacia Publishing; 2002.

5. Perry BD. Traumatized children: How childhood trauma influences brain development. The Journal of the California Alliance for the Mentally Ill 2000;11(1):48-51.

6. Krueger RA, Casey MA. Focus Groups: A Practical Guide for Applied Research Fifth Edition Edition. (5th Ed.). Thousand Oaks, CA: Sage Publishers; 2014.

Acknowledgements - Nil

Conflict of Interest - Nil

Funding - Nil 